\title{
La construcción de la emoción en los discursos políticos de campaña
}

\author{
Sonia Patricia lópez Camargo \\ Estudiante de Doctorado \\ Instituto Tecnológico y de \\ Estudios Superiores de Monterrey \\ Av. Eugenio Garza Sada 2501 Sur, \\ Tecnológico, 64849 Monterrey, \\ Nuevo León (México) \\ E-mail: zonny77@gmail.com
}

\section{LA CONSTRUCCIÓN DE LA EMOCIÓN EN LOS DISCURSOS POLÍTICOS DE CAMPAÑA}

RESUMEN: Los objetivos de este trabajo son la descripción y el análisis del contexto extralingüístico que configura y enmarca a los discursos políticos de campaña de tres candidatos presidenciales ganadores en distintos países de América Latina: Argentina, México y Venezuela durante las campañas electorales que tuvieron lugar entre el 2011 y el 2012 respectivamente. Para ello se parte de la idea de que, a través de elementos como el lugar, la gente que participa, la ambientación o las normas que rigen dichos eventos, todos ellos influyen e incrementan la emotividad en un tipo de discurso que requiere de dicha característica. Mediante la propuesta teórica de Christian Plantin y a través del análisis de seis ejes propuestos por él se muestra como a partir del contexto extralingüístico, el contexto lingüistico se va configurando de manera emocional.

PALABRAS ClAVES: discurso político; campañas electorales; contexto extralingüístico; emoción; América Latina

SUMARIO: 1. Introducción. 2. La relevancia de la democracia. 3.- El discurso y el discurso político. 4 . La construcción de la emoción 5 . Conclusiones.

\section{CONSTRUCTING IN ELECTORAL DISCOURSES}

ABSTRACT: The objectives of this paper are to describe and analyze how the extra-linguistic context configures and frames the political discourses of winner candidates in the presidential elections of three Latin American countries: Argentina, Mexico and Venezuela, in the elections of 2011 and 2012. This article starts from the assumption that elements like the place, the audience, the atmosphere and rules of the event, influence and increase emotionality in specific discourses that require them. We use six different axis from the theoretical proposal of Christian Plantin to show how the extra-linguistic context configures the linguistic context in an emotional way.

KEY WORDS: political discourse; electoral campaigns; extra-linguistic context; emotion, Latin America.

SUMMARY: 1 . Introduction. 2 . The importance of democracy. 3 . Discourse and Political Discourse. 4. Construction of emotion. 5. Conclusions.

\section{LA CONSTRUCTION DE L'EMOTION DANS LES DISCOURS DE CAMPAGNE POLITIQUE}

RÉSUMÉ: Les objectifs de ce projet sont la description et l'analyse du contexte extra-linguistique qui structure et encadre les discours de campagne politique de trois candidats présidentiels gagnants dans divers pays d'Amérique latine: l'Argentine, le Mexique et le Venezuela, pendant les campagnes électorales qui ont eu lieu entre 2011 et 2012, respectivement. Pour ça, on part de l'idée qu'à travers des éléments comme le lieu, les personnes impliquées, l'ambiance ou les règles régissant ces événements, tous influencent et augmentent l'émotivité dans un type de discours qui exige cette caractéristique. On montre comment à partir du contexte extra-linguistique, le contexte linguistique est configuré émotionnellement avec la proposition théorique de Christian Plantin et à travers l'analyse des six axes proposés par lui.

MOTS CLÉS: discours politique campagnes électorales; contexte extra-linguistique; emotion; Amérique latine.

SOMMAIRE: 1 . Introduction. 2 . La pertinence de la démocratie. 3 . Le discourse et le discourse politique. 4. La construction de l'émotion. 5. Conclusions.
Fecha de Recepción Fecha de Revisión Fecha de Aceptación Fecha de Publicación 


\section{La construcción de la emoción en los discursos políticos de campaña}

\section{SONIA PATRICIA LÓPEZ CAMARGO}

\section{INTRODUCCIÓN}

El presente artículo tiene como objetivo un tipo de discurso político específico, aquel emitido durante las campañas electorales. Consideramos relevante su estudio la gran importancia con la que cuentas las campañas electorales para las sociedades democráticas actuales.

Para desarrollar dicho objetivo, se inicia con una descripción de la importancia de los procesos electorales en la actualidad. A continuación, se ofrecen algunos aspectos teóricos sobre lo que debe entenderse por discurso y principalmente por discurso politico. El siguiente paso es el desarrollo de la propuesta teórica de Christian Plantin la cual a través de seis ejes analiticos se describen aquellos elementos situacionales que definen y conforman el contexto en donde se enuncian los discursos políticos de campaña y los cuales imprimen y agregan emoción a un discurso que ya de por sí mismo es emotivo. Como se puede apreciar, se trata de un recorrido que busca mostrar la manera en que el discurso, en específico, el de campaña, se encuentra conformado y definido en gran medida por el contexto extralingüístico.

\section{LA RELEVANCIA DE LA DEMOCRACIA}

Durante el siglo pasado, América Latina transitó hacia la democracia. Así, tras años de largas y cruentas luchas sociales se logró transformar de manera gradual a las dictaduras y sistemas autoritarios en gobiernos cada vez más democráticos, dando con ello paso a formas más trasparentes de elegir a los gobernantes de cada Estado. Y aunque es dificil elaborar una teoría general de las transiciones universalmente válida por las particularidades que en cada Estado se desarrollan, es posible encontrar algunos rasgos que logran evidenciar este cambio.

En primer lugar, se trata de un proceso, -nunca un acto único- que traerá consigo reacomodos en las instituciones, actores politicos y en general en la vida política que permitirán dicho cambio. En segundo lugar, el proceso está conformado por fases consecutivas que van desde el autoritarismo o dictadura hacia la democracia ${ }^{1}$. De lo anterior se desprende que, de acuerdo a los cambios generados, se considera cualquier Estado en un continuum en

\footnotetext{
${ }^{1}$ Es importante mencionar que actualmente no existe un acuerdo entre el número de fases que puede tener el proceso de transición a la democracia, por ejemplo Samuel P. Huntington habla de 9 fases, en cambio para Guillermo O’Donnell y Carl Schmitter son solo 4 o incluso para Adam Przeworski simplemente son dos. No obstante, algo en común es que se trata de un proceso que implica diversas fases que van de lo menos democrático o autoritario a lo más democrático.
} 
proceso de transición, con lo cual podrá ser catalogado como más o menos democrático.

Los casos en los que se enfoca este artículo son tres: Argentina, México y Venezuela; en ellos es posible observar ciertos rasgos que indican dicha transición a la democracia. Por tal motivo encontramos instituciones, actores y actividades politicas que dan muestra de que se trata de Estados en vías de consolidación, siendo la elección popular la más importante de estas señales. Las elecciones para estos tres países se dan a partir de un proceso en donde los ciudadanos eligen de manera libre (a través del voto universal) a las personas que ocuparán cargos políticos de entre una pluralidad de candidatos. Para que los ciudadanos puedan elegir entre dicha pluralidad, el propio sistema político ha creado un lapso delimitado en donde los candidatos pueden exponer sus proyectos políticos y con ello convencer al electorado, es decir, las campañas electorales.

Es importante hacer notar que la manera de elegir a los representantes ha sido un derecho ganado a base de grandes luchas sociales y politicas libradas a lo largo del siglo XX, incluso hoy en dia es un tema importante para cualquier país democrático. De modo que aunque en México las elecciones han existido desde 1857, éstas no siempre han sido ni libres ni tan democráticas como lo muestran el porfiriato y las décadas en que el priísmo logró mantenerse en el poder (González, 1975: 73). La situación en Venezuela es similar, pues, aunque los derechos electorales han estado presentes desde 1943, no podemos decir que en todo este tiempo sus procedimientos para elegir a sus representantes hayan sido totalmente democráticos (Cockcroft, 2001: 445). Y ni qué decir de Argentina, en donde se han elegido representantes desde inicios del siglo XIX, a pesar de que durante casi todo el siglo XX aquellos que ocuparon el poder llegaron gracias a golpes de Estado (Cockcroft, 2001: 660).

Algo similar sucede con las campañas políticas, que no siempre han sido necesarias ni han tenido la estructura con la que cuentan hoy en dia, así, por ejemplo, a lo largo del siglo pasado las campañas en México tenían como principal propósito el difundir la imagen del candidato para buscar la aceptación y apoyo popular, aunque dejaban de lado las propuestas de gobierno y la búsqueda del voto, principalmente porque el resultado de la jornada electoral era solamente un trámite con un final predecible. Hoy en cambio, las campañas políticas se han transformado.

Así pues, la relevancia de este momento trascendental para la vida política de cualquier país democrático radica en el hecho de que las elecciones son el momento más importante para cualquier país que ostente dicha forma de gobierno, sobre todo porque las elecciones no solo permiten conseguir el poder de forma pacífica, sino que, además, el resultado de éstas determinará de manera fundamental el futuro del país y por consiguiente de sus ciudadanos. En consecuencia, para cualquier grupo político que quiera acceder al poder, es necesario ganar la jornada electoral y para ello el mismo sistema politico ha establecido un periodo determinado durante el 
cual todos los aspirantes tienen la oportunidad de ganar la simpatía de los electores.

Por este motivo, durante el periodo en el que se desarrollan las campañas los aspirantes buscan persuadir a los ciudadanos para que les favorezcan con su voto. Como se observa, la magnitud de lo que implican las campañas politicas es tan grande que aquello que logre hacerse durante dicho lapso se verá reflejado de manera inmediata el día de la jornada electoral; pero aún más importante, permitirá ostentar el poder por tres, seis o más años, según sea el caso. Por lo tanto, el interés de centrarnos en este tema radica en la enorme importancia que detentan hoy en día las campañas políticas, motivo por el cual consideramos necesario ahondar más en un hecho tan relevante y que trae consigo tantos cambios.

Sin embargo, es importante advertir al lector que, de todos los rasgos que conforman a las campañas políticas, nuestro interés únicamente se centra en el aspecto discursivo, es decir, en lo que los participantes de dichas campañas emiten durante el periodo proselitista. Partimos del supuesto de que las campañas electorales son periodos de tiempo en los cuales, a partir de diversos contenidos comunicativos, se busca ganar las elecciones. Y, ya que dichos procesos de elección se desarrollan en lapsos relativamente breves (generalmente entre dos y tres meses), es necesario que los contenidos comunicativos sean eficaces para ganar la simpatía del electorado en los plazos estipulados. Es por ello que los candidatos, al buscar conseguir dichos objetivos, transforman sus discursos en una útil herramienta que les permite transmitir información al electorado y así persuadirlos a votar a su favor.

De manera particular este trabajo tiene como objetivo el estudio del discurso político de campaña enfocado en la región de América Latina. Para ellos se buscará un acercamiento con ciertos rasgos que poseen los discursos de tres candidatos exitosos que lograron ganar las elecciones presidenciales de su país: en Argentina con Cristina Fernández de Kirchner; en México con Enrique Peña Nieto y Venezuela con Hugo Chávez Frías, tal y como se observa en el corpus discursivo que más a delante se describe.

\section{EL DISCURSO Y EL DISCURSO POLÍTICO}

La noción de discurso que se asume para el presente artículo es la de considerarlo como algo más que su acepción lingüística (es decir, como un conjunto de oraciones que tiene como finalidad describir una realidad), y asumirlo, más bien, desde una perspectiva en donde el discurso es visto como una acción social, el cual crea algo en el momento mismo en el que se está hablando (Foucault, 2002:13; Haidar, 2002: 74 y Wodak, 2003:104) . Esta forma de conceptualizar al discurso implica consideraciones tanto teóricas como metodológicas importantes que necesitan ser tomadas en consideración. La primera de ellas es que se trata de una organización transfrás- 
tica, que se encuentra regido por normas tanto institucionales como lingüísticas. En sungo lugar, se trata de una forma de acción la cual está siempre inmersa en un contexto o situación histórica.

Una vez que sabemos lo que debe considerarse por discurso, es necesario definir el género discursivo en el que queremos enfocarnos, el político. Al igual que el concepto de discurso, el discurso político cuenta con diversas definiciones que están relacionadas a los objetivos de quien las utiliza. En este caso tomaremos como punto de partida la idea desarrollada por Elíseo Verón en su escrito La palabra adversativa quien nos permite ahondar en el tema del discurso político al considerarlo, más que un tipo de discurso, un campo discursivo enfocado en lo político, en sus propias palabras “...una tipología de juegos discursivos enfocados a la política..."(1987: 14). A pesar de que nuestro objetivo no se centra en el discurso politico en general, sino en un género en particular, aquel que se emite únicamente durante las campañas politicas, creemos que nuestro estudio puede contribuir a mostrar uno de los juegos discursivos a los que se refiere Verón.

Otra definición que nos ayuda a entender al discurso político es la de Norman e Isabela Fairclough, quienes lo definen como “...una práctica argumentativa que permite ver de qué manera es posible convencer a la audiencia de tomar cierto curso de acción a favor de tal o cual propuesta..." (2012: 17). Esta forma de definir este género discursivo se debe sobre todo a que, para estos autores, la politica se centra fundamentalmente en las lineas de acción que nos permitan responder a determinadas circunstancias y objetivos. Es por ello que este tipo de discurso nos muestra las estrategias que los emisores emplean a fin de convencer al auditorio de llevar a cabo cierta acción (2012: 17), en este caso votar por ellos y apoyar su campaña. Así pues, esta definición enfoca una característica importante para este trabajo, la de que se trata de un tipo de discurso argumentativo que persigue cierto fin, el de la persuasión del electorado. Y es precisamente este objetivo el que a continuación se desarrollará.

No hay que olvidar, que a diferencia de otro tipo de discurso, el discurso político no pretende establecer una verdad por medio de la razón, ese no es su objetivo, sino el de intentar "transformar o fortalecer opiniones", marcadas por la emoción. De allí radica que en el discurso político encontremos una mezcla entre razón y pasión, a fin de poder persuadir al ciudadano de adherirse a determinado valor, e incluso, de manera más particular, el de exhortar el individuo de afiliarse con determinada propuesta política. Y el pasar del ser al hacer, implica un mayor trabajo, el cual no es posible lograr a partir de una presentación de plataformas y valores políticos, es necesario, además, que la selección y presentación de los valores sea expuesta mediante una "escena dramatizada" que esté repleta de emotividad (Charaudeau, 2009: 277), se trata pues de utilizar todo lo necesario a fin de convencer al ciudadano de actuar y qué mejor que apelar a las emociones del individuo. Incluso, es el propio Charaudeau quien nos incita a centrar el análisis del discurso a identificar los rasgos emotivos que conforman a esta tipología 
discursiva, objetivo que aquí se retoma, aunque centrado esclusivamente en América Latina.

\subsection{Corpus discursivo}

Antes de iniciar con el tema de la emoción, es necesario detenernos en la conformación del corpus utilizado para el análisis aquí propuesto. Los discursos aquí seleccionados se tratan de emisiones pronunciadas únicamente por los candidatos exitosos que lograron ganar las elecciones presidenciales de Argentina, México y Venezuela dejando con ello de lado a otros candidatos más que no ganaron. Además de esta primera selección, otro rasgo a considerar ha sido la temporalidad; así pues, los discursos aquí analizados fueron emitidos durante el periodo 2011-2012, lapso en el cual los tres países en cuestión se encontraban en campaña política presidencial.

Una vez que se tomó en cuenta ambas características, se conformó un corpus discursivo de nueve discursos que además cumplieran con tres criterios específicos. El primero de ellos es que puedan mostrar el inicio de las campañas politicas; el segundo criterio, que se trate de un discurso emitido a mitad de la campaña pero que, además, haya sido dirigido a los simpatizantes partidistas de los candidatos en cuestión ${ }^{2}$; y finalmente, el tercer criterio muestre la manera en que terminaron dichos procesos políticos. El motivo de elegir estos criterios es que a partir de ellos se pueda observar de manera panorámica la campaña en cuestión, al presentar cómo inician, se desarrollan y concluyen las jornadas electorales en palabras de los propios candidatos. Adicionalmente, el segundo criterio también permite restringir el auditorio analizado, al enfocarse en los simpatizantes partidistas de los candidatos. El motivo de considerar tantos aspectos en la selección del corpus se debe a la necesidad de establecer parámetros que homogenicen las emisiones a fin de poderlas analizar y comparar, transformando así un conjunto de emisiones heterogéneas en un cúmulo más uniforme más allá de la lengua y de los sistemas politicos análogos.

No obstante, es necesario advertir al lector que los discursos seleccionados también cuentan con ciertas diferencias, sobre todo en lo referente a su duración, así, por ejemplo, en el caso de los discursos emitidos por el candidato mexicano, éstos tienen una duración aproximada de 5 minutos, los de Cristina Fernández de Kirchner de 20 minutos, mientras que los del candidato venezolano tienen una duración de más de dos horas cada uno.

Una vez mencionadas las similitudes y diferencias, se presenta la conformación del corpus:

Para el caso de la candidata argentina se seleccionaron los siguientes discursos:

\footnotetext{
2 Partido Revolucionario Institucional, Partido Socialista Unido de Venezuela y el Frente para
} la Victoria, respectivamente. 
1.-Confirmación de la candidatura a la reelección $(21 / 06 / 2011)^{3}$

2.-Discurso de triunfo fórmula Cristina Kirchner-Boudou en las Primarias Abiertas Obligatorias $(15 / 08 / 2011)^{4}$

3.- Cierre de campaña 2011 en el Teatro Coliseo $(19 / 10 / 2011)^{5}$

En el caso de México los discursos que se eligieron fueron:

1.- Discurso de inicio de campaña $(29 / 03 / 2012)^{6}$

2.- Discurso emitido durante la XXX Sesión Extraordinaria del Consejo Político Nacional en el CEN del PRI $(25 / 05 / 2012)^{7}$

3.- Discurso de cierre de campaña en el Estadio Azteca $(24 / 06 / 2012)^{8}$

Finalmente, para el candidato venezolano los discursos ${ }^{9}$ son:

1.- Inscripción de la Candidatura de la Patria (11/06/2012)

2.- Reunión con la maquinaria electoral del PSUV (7/09/2012

3.- Cierre de campaña: concentración y caravana en apoyo al candidato de la Patria (4/10/2012)

\section{LA CONSTRUCCIÓN DE LA EMOCIÓN}

Aunque por mucho tiempo el tema de la emoción fue desterrado del estudio argumentativo, a partir de la neoretórica y de otras aportaciones más recientes, el tema de la emoción se ha incluido en los estudios de la argumentación. Entre dichos estudios está el de Michael Gilbert quien desarrolla la Argumentación Coalescente. Este tipo de argumentación parte de la idea de que las emociones cuentan con un propósito fundamental, ya que no solo sirven para comunicar a nuestro interlocutor "el grado de compromiso, preocupación y sensación que uno tiene sobre un punto de vista determinado" (1997: 4) sino que además, nos ayudan a determinar si un punto de vista está conectado a otros asuntos mucho más urgentes que deben ser considerados antes de concluir la argumentación. Así y gracias a las argumentaciones emocionales es posible pasar de asuntos superficiales a otras consideraciones más profundas. De igual manera, Gilbert nos advierte que los argumentos emocionales adquieren su importancia no solo de lo que se emite, sino del contexto en que se emite y del propio argumentador. Esto es

\footnotetext{
${ }_{3}$ Transcripción propia tomada del video del canal de YouTube de la Casa Rosada de Argentina https://youtu.be/975F7YwER6U.

4 Transcripción propia tomada del video del canal de YouTube Fuerza Cristina2011 https://youtu.be/XrOmHV2_7Gg.

5 Consultado en https://www.cfkargentina.com/cfk-en-el-teatro-coliseo-cierre-de-campana$2011 /$.

6 Consultado en http://informadorbcs.com/uncategorized/vea-aqui-el-discurso-integro-delarranque-de-campana-de-pena-nieto/.

7 Consultado en la página oficial del PRI:

http://pri.org.mx/SomosPRI/saladeprensa/Nota.aspx?y=6838.

8Consultado en la página oficial del PRI:

http:// pri.org.mx/SomosPRI/saladeprensa/Nota.aspx?y=7185

9 Todos han sido tomados del Blog "Chávez, corazón de mi patria" (blog.chavez.org.ve) y contrastados con los videos de los discursos que hay en YouTube.
} 
precisamente nuestro punto de partida para el desarrollo teórico que continuación se presenta, dado que nuestro interés es mostrar la manera en que a partir del contexto extralingüístico se va conformando la emoción en la argumentación. No olvidemos que el objetivo de este trabajo está centrado en una tipología discursiva que recurre a la emoción como recurso para conseguir su objetivo, el de persuadir al ciudadano de actuar, o en nuestro caso, de votar por determinada propuesta politica, tal y como se observa en el discurso emitido durante las campañas electorales latinoamericanas.

Para iniciar con el fenómeno extratextual, se utilizará el modelo propuesto por Christian Plantin, a fin de realizar una aproximación que permita la reconstrucción de la situación emocional. Con ello se busca mostrar el conjunto de factores o circunstancias que provocan alguna reacción, ya sea de forma positiva o negativa en aquellos que escuchan dicha emisión. Para tal motivo el teórico francés propone el análisis de seis ejes a través de los cuales se puede acceder a esta reconstrucción ${ }^{10}$, los cuales serán desarrollados a continuación.

\section{A) Tipo de Evento}

Existen ciertos eventos que por sí mismos remiten a estados eufóricos (como el de una boda, una fiesta o un nacimiento) o su contrario, disfóricos (un sepelio, un divorcio, una despedida). Se trata de acontecimientos preconstruidos que remiten a reacciones positivas o negativas. Sin embargo, en ocasiones también es importante tener en consideración otras circunstancias además de las ligadas al hecho en sí. Por ejemplo, la despedida remite a un hecho triste, sin embargo, si se trata de la despedida de una persona molesta, la despedida puede convertirse en un evento positivo y hasta jubiloso. Por consiguiente, Plantin considera necesario iniciar por la descripción del tipo de evento, "aclarar de qué tipo se trata, para así iniciar una descripción lo más profunda posible de las emociones involucradas" en el mismo (Plantin, 2011: 198).

En el caso de los discursos de campaña los tres casos estudiados se tratan de eventos completamente eufóricos, de alegria y esperanza, que han de mostrar esa euforia y transmitirla a los oyentes para buscar convencerlos de formar parte del proyecto político; así como de persuadirlos a realizar ciertas acciones (ya sea que se trate de promover el voto o bien acudir a votar, según sea el caso). Ahora bien, la manera en que los emisores buscan expresar esta euforia en los eventos transciende el discurso: el lugar, la gente que participa, el cómo va vestida, la ambientación del lugar, todo ello influye y transforma al acto en un evento eufórico, como se verá en los siguientes apartados.

\footnotetext{
10 A pesar de que Plantin propone 12 ejes, de los cuales, uno se eliminó debido a que se duplicaba con la variable 4-el de la distancia-, en cambio los otros tres no tienen cabida para el tipo de discurso que se desea estudiar - placer, consecuencia y control; y, finalmente, en la variable 4 se unen dos ejes (tiempo y lugar).
} 


\section{B) Personas involucradas}

La emotividad de un evento siempre está ligada a la percepción de las personas, sobre todo porque, tal y como advierte Plantin, un mismo suceso puede provocar diversas reacciones emocionales de acuerdo a la identidad de las personas involucradas. La principal razón es que "la emoción varía con la identidad de las personas afectadas, ya que ciertas personas son emocionalmente más sensibles que otras frente a un mismo acontecimiento" (2011: 198) o bien despiertan emociones diferentes en los demás. Por tal razón se convierte necesario describir a los individuos que participan en la situación emocional de interés.

En el tipo de discurso que nos ocupa aquí, se puede observar en los tres casos analizados la presencia de una persona en común, el orador. Lo que se debe, en gran medida, a que se trata de emisiones que tienen como primer objetivo la autoconstrucción del orador. Lo anterior se explica por la importancia que tiene el emisor, pues es él quien abandera el proyecto político y el que se está autopromoviendo, ya sea que se trate del Partido Justicialista (PJ), del Partido Revolucionario Institucional (PRI), Partido Socialista Unido de Venezuela (PSUV) o de cualquier otro partido político. Aunque dicha institución por sí misma implique una gran tradición social y política, como es el caso del Justicialista por ejemplo o el del PRI mexicano, de cualquier forma, el proyecto político recae en una sola persona, el candidato. Por ello, el discurso de campaña tiene como característica el enfocarse en el emisor. Por consiguiente, una de las características de este tipo de discurso político es la de centrarse siempre en el orador, es decir, en la autoconstrucción del político encargado de emitir el discurso. Por este motivo se observan grandes esfuerzos dedicados a esta autoconstrucción, sobre todo porque ésta irá cambiando conforme el tiempo de campaña avance o las circunstancias lo requieran.

[1] Cada vez menos gente cree en las promesas que hacen los políticos. Por eso, allá, en lo que fue mi campaña para Gobernador hace siete años, decidí innovar la forma de hacer política, asumiendo compromisos. En esta campaña, la que hoy inicio aquí en Guadalajara, volveré a firmar compromisos con todo México. Voy a certificarlos ante Notario Público, pero lo más importante, como Presidente los voy a cumplir (Discurso de Inicio de Campaña, §30-§31).

[2]Me enorgullezco como latinoamericana y como suramericana frente a otros escenarios donde nadie resuelve nada y que, por el contrario, complican todo todos los días con más violencia. Me enorgullezco, de haber estado allí y ser parte de la UNASUR y que él, en su última misión como Secretario General de la misma, contribuyera a la paz entre la hermana República de Colombia y la hermana República Bolivariana de Venezuela (Cierre de campaña en el Teatro Coliseo, §27).

[3] por eso es que yo digo con mucho respeto, católico y cristiano como soy que, esto ha venido de milagro en milagro. Que hemos venido de milagro en milagro. Un día como ayer, me operaban la primera vez. A los pocos dias llegó Fidel y me dijo: Chávez, tienes cáncer, ¡uff! Aquello fue terrible, yo pensé que todo se acababa, pero igual soldados 
somos y en el camino vamos; y la otra operación, y la otra, y un año después estoy aquí frente a ustedes en la Plaza Diego Ibarra, inscribiendo la candidatura para la gran victoria del 7 de octubre (Inscripción de la Candidatura de la Patria, Pág. 21).

En el Fragmento 1 se puede apreciar la manera en que Peña Nieto decide autodescribirse como un político moderno, pero que además sabe cumplir compromisos y para ello ofrece como prueba lo que realizó durante su campaña anterior para gobernador del Estado de México, en donde firmó ante notario público sus compromisos de campaña. Esta forma de descripción, además le permite al priísta mostrar que no es un político improvisado, sino que cuenta con experiencia. Respecto del caso argentino, la candidata apuesta por destacar su origen latinoamericano (como se observa en el Fragmento 2) en cambio, Hugo Chávez decide autodescribirse a partir de su estado de salud, lo que le permite mostrar que a pesar de todos los problemas físicos por los que atraviesa, él desea seguir dirigiendo al país (Fragmento $3)$.

La segunda persona involucrada en este tipo de discurso político es el auditorio: Ya sea que se trate de público en general o de partidarios, ellos siempre estarán incluidos en el discurso. Lo anterior en gran medida por la necesidad de incorporar al oyente, al menos dentro del discurso, en el proyecto político, hacerlo sentir parte del equipo, o al menos de lo que se está buscando mejorar. Es por este motivo que en todos los discursos analizados encontramos referencias al auditorio, tal y como podemos observar en los siguientes fragmentos:

[4] A todos ustedes, a quienes nos acompañan aquí en Guadalajara, a quienes nos siguen por Internet y los medios electrónicos, les digo que a partir de este momento, todos somos promotores del cambio que México necesita (Inicio de campaña de EPN, §7)

[5] ¡Fuerza Argentina!, ¡Fuerza!, acá estamos para sostener lo que hemos construido, y acá están ustedes para defenderlo porque es de todos, de todos los argentinos, de los 40 millones de argentinos (Discurso emitido en el Teatro Coliseo para el FpV, §36)

En el Fragmento 4 se puede observar que el candidato priísta busca mencionar a la mayor cantidad de mexicanos posibles, por tanto, no solo se refiere a los que se encuentran presentes en aquel evento, sino también hace referencia a aquellos que siguen la transmisión, todo ello con el fin de buscar hacer sentir como parte del proyecto a todos, incluso a los que no pudieron estar en el inicio de campaña. En el caso de Cristina Fernández, se observa en el Fragmento 5 que la candidata hace referencia a todos los argentinos, sin importar si simpatizan o no con su propuesta.

Ahora bien, además de las dos personas antes mencionadas, existen dos casos importantes que cuentan con una frecuencia de aparición muy alta al interior de los discursos, por lo que es necesario su mención. Se trata de los majunches venezolanos, y en el caso argentino, de Néstor Kirchner. 
El grupo burgués al que Chávez se refiere como los “majunches” (término con implicación negativa ${ }^{11}$ ) se trata de un grupo politico sumamente importante en el discurso del candidato venezolano, debido a que es empleado como punto de contraste para su propuesta politica. Así, gracias a este grupo, Chávez puede autodefinir su propuesta politica de manera maniquea tal y como se puede observar en los siguientes fragmentos:

[6] De allí que vamos a seguir fortaleciendo el poderío militar de la nación. ¿Cuál es el proyecto de los majunches? Lo contrario, desarmar al país como ya lo habian hecho en el pasado. Venezuela no tenía en verdad una Fuerza Armada, en 1998, no, había unos militares y unas unidades. Yo recuerdo, bueno los aviones casi no volaban, los tanques creo que algunos rodaban pero para atrás, tenían sólo retroceso, los pocos tanques que rodaban, los fusiles ya no servian unos viejos fusiles. Ve, entonces vamos a continuar equipándonos, fortaleciéndonos en lo moral, la Fuerza Armada y además, las milicias con el Ejército, la Marina, la Aviación, la Guardia Nacional, las Milicias Bolivarianas y todo el pueblo; la defensa es un problema de todo el pueblo bolivariano (Inscripción de la candidatura de la patria, Pág. 18).

[7] Porque ellos saben que no podrán cambiar la Constitución, ellos saben que en función de este plan no podrán cambiar muchas leyes revolucionarias que hemos venido aprobando desde la Asamblea Nacional y también desde el Gobierno en Habilitante, entonces dicen con mucha claridad por aquí, documentos que estaban escondidos, el paquete oculto, lo dicen clarito allí y lo firmó el majunche, ahora lo niega, dicen que mientras se puedan cambiar las leyes habrá que recurrir a instrumentos sub-legales, decretos y otras medidas para ir desmontando lo que ellos llaman "el andamiaje legal inconstitucional" lo dicen ellos, las leyes pues, la Ley del Poder Popular, la Ley de los Consejos Comunales, de la Economía Comunal, las leyes de las misiones, como la Ley de la Misión Vivienda, la Ley de Bancos que establece tope a las carteras obligatorias y a los intereses. Plantean aquí la liberación de los intereses bancarios ¡claro! Claro que sí, pero ¿quiénes financian al Majunche? ¡Los grandes banqueros! Y entre otros los banqueros prófugos. Plantean la liberación de los precios de la energía eléctrica, del agua, del Metro, el Metrocable, los ferrocarriles ¡todo eso está planteado aquí! Y mucha gente no lo sabe. Vayamos a explicar, a difundir el verdadero programa oculto del candidato burgués ¡un paquetazo que llevaría a Venezuela a una guerra civil de verdad! (Reunión con la maquinaria del PSUV, Pág. 17).

Como podemos observar, el grupo político burgués se convierte en un punto importante, no solo para los discursos, sino para la campaña en general. Por tal motivo, sus referencias a este grupo son muchas y por ello no podía quedar fuera de este análisis. Sobre todo, porque el mencionar dicho grupo se asocia con hechos o situaciones dolorosas, aquellas circunstancias que han lastimado al pueblo venezolano por mucho tiempo, logrando con ello despertar emociones en su auditorio.

La segunda persona importante que se puede encontrar en los discursos de la candidata argentina es Néstor Kirchner. Incluso, fue tan importante que hasta se convirtió en un hilo argumentativo de la campaña ${ }^{12}$, motivo

\footnotetext{
11 De acuerdo a la RAE, se trata de un adjetivo coloquial venezolano utilizado para describir algo de calidad inferior, deslucido o mediocre.

12 A tal grado que Daniel Scheinsohn, especialista en marketing y ex-OSDE, denominó como "necromarketing" a esta campaña debido a que está basada en el recuerdo de la figura de Néstor Kirchner.
} 
por el cual se encuentra en todos los discursos de la candidata argentina. A continuación, algunos ejemplos de ello:

[8] La verdad que me costaría estar en el Teatro Argentino. Tal vez cuando pase un tiempo pueda volver, pero me costaría estar en el Teatro Argentino, levantar la vista y no encontrarlo. Porque, aunque ustedes no lo crean, cuando hablábamos los dos ante auditorios o ante actos, obviamente uno habla para comunicar sus ideas a los que están alli y a la sociedad, pero entre los dos siempre hablábamos un poco cada uno y, enseguida, buscábamos la mirada de aprobación en el otro sobre lo que habiamos dicho. Natural después de casi 36 años de militar juntos; es también algo inigualable. (Confirmación a la candidatura, §46).

[9] Esto es lo que está sintiendo mucha gente en todo el mundo, que los gobiernos no los representan, que sus intereses son diferentes a los de los gobernantes, y yo creo que el gran mérito que supo tener él fue construir, fue construir está Argentina que había sido devastada, pero no solamente devastada económicamente, sino devastada moral y culturalmente, él supo construir la confianza del pueblo en sus gobernantes, algo imprescindible para que toda sociedad civilizada pueda avanzar y crecer (Discurso emitido en el Teatro Coliseo para el FpV, §34).

Estos ejemplos nos permiten conocer un Néstor ${ }^{13}$ polifacético, un político capaz de reconstruir una Argentina devastada (Fragmento 9), valiente, trabajador, e incluso hasta mártir, ya que fue capaz de dar su vida por el país, pero, sobre todo, una pareja inigualable para la candidata y por ello es que le es tan dificil superar su pérdida (Fragmento 8).

Como hemos podido notar, este tipo de discurso político hace énfasis forzosamente en dos personas, sin importar si se trata de un discurso de inicio, cierre o mitad de la campaña, pues en cualquiera de ellos lo que se busca es, en primer lugar, la autoconstrucción del emisor y en segundo lugar, hacer sentir al auditorio como parte del proyecto político que se propone. Lo anterior explica la gran reiteración de la presencia del emisor y el auditorio en este tipo de discurso político. No obstante, pueden surgir algunas figuras importantes al interior del discurso, pero éstas han de perseguir otros fines específicos, como se mostró con el caso del grupo burgués venezolano y el uso de la figura de Néstor Kirchner.

\section{C) EJE DE INTENSIDAD/CANTIDAD}

Este tercer eje puede afectar a categorias tales como la distancia, el tiempo o la calidad de las personas, al "tratarse de una modulación cuantitativa que afecta dichas categorias" (2011: 198) y que impacta en la percepción de la audiencia. Así, por ejemplo, no es lo mismo poco tiempo o muchísimo tiempo; unos cuantos metros o a kilómetros; un herido o 500 heri-

\footnotetext{
13 Es importante remarcar que aunque la candidata argentina se refiere a Néstor en muy pocas ocasiones lo menciona por su nombre, en cambio la mayoría de las veces lo hace mediante el pronombre "él" y en otras como pingüino, no obstante, todos los argentinos saben que se refiere a su difunto esposo.
} 
dos tras un accidente. Es por ello que este recurso es utilizado constantemente en los discursos que buscan ser emotivos ya que permite la "dramatización retórica" (Plantin, 2011: 198).

En el caso que nos atañe, el del discurso de campaña política observamos que este tercer eje puede ser positivo o negativo, según los intereses del emisor y del tipo de elección que se trate. Así, por ejemplo, si el candidato busca por primera vez el puesto político y el grupo en el poder es el mismo que el suyo, entonces el eje será positivo, pues estará enfocado en los aciertos que ha tenido la actual administración. En cambio, si el grupo en el poder es un partido opositor, entonces el eje será negativo y se enfocará en hacer notar todos los errores que han cometido otras administraciones, tal y como podemos observar en el siguiente ejemplo:

[10] Duele reconocerlo, pero México no vive un buen momento. Muchos mexicanos atraviesan tiempos dificiles, sienten incertidumbre y desesperación. México está herido por la inseguridad y la violencia. Muchos mexicanos viven angustiados y, lo que es peor, viven con miedo. Los más afectados son nuestros niños. Ahora en nuestros niños, sus temores ya no sólo están en su imaginación: están afuera de su escuela, en las calles, donde antes jugaban con sus padres. La violencia ya no es sólo una fría estadística, cada vez son más las familias afectadas de manera directa con la desaparición y asesinato de un ser querido.Hay un México con enorme pobreza, con millones de familias a quienes no alcanza ni lo más mínimo para comer.Hay un México con una economía incapaz de generar buenos empleos y, sobre todo, oportunidades para todos los mexicanos... (Inicio de campaña EPN, §12-15)

En el Fragmento 10 se puede apreciar la manera en que Enrique Peña aprovecha la mala situación que doce años en el poder de Acción Nacional han dejado al país: inseguridad, marginación, pobreza, problemas económicos, en fin, todos los problemas que aquejan al pais y que son utilizados por Peña Nieto como punto de referencia de todo lo que podría cambiar en caso de llegar al poder.

En cambio, si el candidato busca una reelección, dificilmente tendrá una postura negativa, sin importar la mala situación en la que se encuentre el país en cuestión, pues sería como renegar de su propio gobierno. En este caso se evitará el tema o se enfatizarán los aciertos que se han logrado hasta el momento y todo aquello en lo que hay que seguir trabajando a fin de continuar mejorando la situación del país, como se puede observar a continuación:

[11] Estos son los lugares y los espacios en que esta Presidenta quiere estar; estos son los hombres y mujeres, más el resto de los millones de argentinos, que quiero seguir trabajando porque sé que faltan cosas. Necesitamos construir más escuelas, pese a que hemos construido más de 1.200 escuelas; necesitamos más viviendas, más allá de que hemos dado soluciones habitacionales a más de 800.000 hogares argentinos; necesitamos más megavatios para seguir creciendo a pesar de que hemos ya producido más de 8.100 megavatios más de los que teníamos; necesitamos más hospitales; necesitamos más rutas; necesitamos también más fábricas y por eso tenemos que seguir trabajando para que haya más trabajo argentino (Cierre de campaña en el Teatro Coliseo, §28). 
Así, a diferencia de Peña Nieto, Cristina Fernández no puede hablar mal del gobierno en turno por varias razones. En primer lugar, porque se trata de su administración. Y, en segundo lugar, porque el gobierno anterior fue el de su difunto esposo; es decir, ambos pertenecientes el Partido al que pertenece la candidata argentina, al Justicialista. Sin embargo, existen cosas que no puede ocultar, por ello se ve en la necesidad de mencionarlas, como se observa en el Fragmento 11 . No obstante, dicha mención la utiliza como punto de referencia para hacer énfasis en lo que trabajará durante su siguiente gobierno, en caso de seguir ella en el poder.

\section{D) EJE ESPACIO/TIEMPO}

El siguiente eje está conformado por dos categorias que nos ayudan a situar al auditorio respecto del discurso. La primera de ellas se trata del lugar de emisión del discurso, debido a que "el lugar puede estar emocionalmente marcado, ya sea por el lugar en sí mismo o en relación a una persona determinada" (2011: 199). Por tal razón es necesario describir de forma detallada el lugar en donde se produce la emoción y sus influencias en la audiencia.

En cambio, la segunda categoría, la del tiempo, se encuentra enfocada en la descripción del lapso en el que se suceden los hechos que se narran. Lo anterior se debe principalmente a que la construcción temporal y aspectual permite incluir o excluir a quien escucha. Así por ejemplo, si se menciona de un evento que ocurrió hace más de cien años, el auditorio no habrá sido participe, en cambio, si se habla de un hecho que ha ocurrido hace algunos días o la semana pasada, es más probable que sí haya participado y con ello se sentirá más ligado al discurso (Plantin, 2011: 179).

Respecto a la primera categoria, la del lugar, se trata de un punto trascendental, debido a que el espacio en donde se realiza el evento determina en gran medida al discurso. Por tal motivo, el equipo de campaña propone lugares emblemáticos para llevar a cabo ahí los eventos de campaña y con ello dotar de significados a la emisión discursiva.

Así pues, el espacio de emisión no es un lugar tomado al azar ya que desde ahí empieza la construcción de la emotividad del discurso. Lo anterior explica la razón por la cual los discursos que emite Hugo Chávez fueron pronunciados en lugares históricos e importantes dentro de la capital venezolana a tal grado que incluso lo incluye en su discurso:

[12] Bueno miren en verdad estamos cerrando campaña hoy de esta manera esplendorosa, desbordada de amor, de Patria, de alegría en Caracas la cuna de Bolívar, Bolívar, Bolivar... yo le doy gracias a Dios, le doy gracias a la vida como dice la canción, gracias a la vida por haberme dado tanto jaquí está Chávez de pie con ustedes! (Discurso de cierre de campaña en la Avenida Simón Bolivar, pág 2).

Como se observa en el Fragmento 12, el candidato venezolano utiliza el nombre de la Avenida en donde se encuentra ubicado en el momento de 
emitir su discurso, ello con el fin de rememorar al héroe sudamericano y así darle mayor emotividad a su discurso y al mismo tiempo remarca nuevamente la importancia que tiene la historia para dicho movimiento político.

En el caso de la candidata argentina, es posible encontrar la importancia que cobra el lugar en donde se emite el discurso, al grado de incluirlo dentro de la propia emisión, como se puede observar en el siguiente fragmento:

[13] La verdad que me costaría estar en el Teatro Argentino. Tal vez cuando pase un tiempo pueda volver, pero me costaria estar en el Teatro Argentino, levantar la vista y no encontrarlo. Porque, aunque ustedes no lo crean, cuando hablábamos los dos ante auditorios o ante actos, obviamente uno habla para comunicar sus ideas a los que están alli y a la sociedad, pero entre los dos siempre hablábamos un poco cada uno y, enseguida, buscábamos la mirada de aprobación en el otro sobre lo que habíamos dicho. Natural después de casi 36 años de militar juntos; es también algo inigualable (Confirmación de la candidatura a la reelección de Cristina Fernández de Kirchner, §46).

En este Fragmento 13 la mención del lugar le sirve en primer lugar para justificar la razón de llevar a cabo dicho evento en la Casa Rosada y no en un lugar más emblemático como es el caso del Teatro Argentino, pero sobre todo para nombrar una vez más a su difunto esposo y expresidente argentino, Néstor Kirchner (buscando con ello mover emociones en su auditorio, pues nuevamente asume su papel de viuda que aún extraña a su esposo y compañero político ${ }^{14}$.

Respecto de la segunda categoría, la del tiempo, es importante remarcar que algo que se encuentra en todos estos discursos de campaña es la referencia al tiempo presente. Lo anterior debido a que es necesario referirse a la campaña: a sus errores, a sus aciertos, a los problemas que están teniendo, a todo lo relacionado con la campaña y su desarrollo. Por ello, tanto en los discursos de inicio, mitad y cierre de campaña, se menciona, en mayor o menor grado, el tiempo presente y con ello la campaña. Esto lo podemos observar en los siguientes ejemplos:

[14] Ahora bien podemos también nosotros militantes de la causa humana, hacer brevemente como un repaso, como un resumen de los dos meses de campaña que hemos transitado, nuestra campaña. Nuestra campaña ha significado muchas cosas, pero uno pudiera decir, uno pudiera graficarla así, grosso modo, ha sido una campaña de propuestas; ha sido una campaña transparente; ha sido una campaña de sumatoria de fuerzas; ha sido una campaña donde nosotros hemos estado claramente explicando, respondiendo preguntas, escribiendo propuestas... (Reunión con la maquinaria electoral del PSUV, Pág. 10).

[15] Sé que en esta campaña participan miles de militantes y líderes sociales, quienes llevan nuestra propuesta de cambio a sus barrios y comunidades; quienes dan la cara y se la juegan con el partido, con el PRI. Yo sé que detrás de esta candidatura está la pasión, la energía y el compromiso de simpatizantes, de mujeres, jóvenes y hombres, que llevan nuestro mensaje de esperanza por todo el país (Sesión Extraordinaria del Consejo Politico Nacional en el Comité Ejecutivo Nacional del PRI, §9).

${ }^{14} \mathrm{El}$ caso del candidato mexicano no es mencionado debido a que si bien el emisor sí menciona el lugar en que es emitido el discurso, el lugar no cuenta con una carga emocional tan fuerte como los otros dos casos, por ello se prefirió omitirlo. 
En ambos fragmentos, se puede observar que tanto Hugo Chávez, como Enrique Peña Nieto, se toman el tiempo para referirse a la campaña, pero no de manera abstracta, sino en relación a ella, a las acciones que se han realizado, a la manera en la que va desarrollándose la misma. Lo anterior resulta importante para seguir recordándole al auditorio su relevancia.

Asimismo, el presente también es utilizado para hablar de la situación del país en que se realiza la elección, en este caso se puede hablar bien o mal del presente, de acuerdo al tipo de elección que se trate, tal como se observó en el eje de intensidad/cantidad.

Ahora bien, respecto a la referencia al pasado, se puede observar que su utilización no es generalizada, incluso en ocasiones hasta puede ser omitida. La razón de esto es que dicho tiempo puede implicar la rememoración de errores cometidos por el partido que abandera al propio candidato. El ejemplo más claro de esto se encuentra en el discurso de Enrique Peña Nieto, que, por ser abanderado por el PRI, y dada la mala imagen que tenía dicho partido en ese momento, el político mexicano decide hacer una mención mínima del mismo, como se puede observar a continuación:

[16] El PRI tiene que asumir el papel que le corresponde, no inspirado en la nostalgia del ayer, sino en los retos del presente, para ganar el futuro (Sesión Extraordinaria del Consejo Político Nacional en el Comité Ejecutivo Nacional del PRI, §11).

[17] Soy el primer convencido de que es momento de superar viejos paradigmas y plantearnos nuevas formas de hacer las cosas, de asumir las tareas y nuestras responsabilidades para cumplirle a los mexicanos. Es la hora de romper con el pasado (Sesión Extraordinaria del Consejo Político Nacional en el Comité Ejecutivo Nacional del PRI, §19).

En estos ejemplos se puede observar que el tema del pasado es un asunto delicado para este candidato, por consiguiente, busca limitarlo lo más posible, y, en caso de mencionarlo, hacerlo de la manera más disimulada posible, evitando hablar de los errores del pasado y en cambio resaltar la nostalgia del ayer o de viejos paradigmas (Fragmento 17).

No obstante, no a todos les incomoda o preocupa el pasado, incluso para algunos es importantísimo, como es el caso de Hugo Chávez, quien basa, no solo su campaña, sino su movimiento político en general en la historia. Por tal razón, observamos una gran cantidad de referencias a dicho tiempo en cualquiera de sus discursos politicos, tal y como se puede apreciar en los siguientes fragmentos:

[18] aclarar de dónde venimos, de dónde venimos nosotros, nosotros no ocultamos eso. Nosotros venimos de allá de Santa Marta, y antes, venimos de allá del grito de Guaicaipuro; venimos de allá de las Sierras de Falcón...Venimos de allá de "El Porteñazo", de "El Carupanazo", venimos de "El Caracazo", venimos del 4 de Febrero, venimos del 27 de Noviembre, de ahí venimos nosotros.No tenemos por qué ocultar nuestros orígenes, nosotros somos del pueblo, somos parte del pueblo, somos campesinos, somos obreros, obreras, pescadores, pescadoras, juventud estudiosa. Nosotros somos y decimos lo que somos, y además estamos orgullosos de lo que hemos sido, y de lo que somos, orgullosos. Orgullosos aún de los errores cometidos; orgullosos aún de nuestros peores pasos, 
pero somos orgullosos, y además somos responsables por lo que hemos sido, no negamos para nada, todo lo contrario, lo develamos, nuestros orígenes, nuestro camino, nuestra trayectoria, nuestras ejecutorias (Reunión con la maquinaria electoral del PSUV, Pág. 10).

[19] Nosotros venimos de lejos, nosotros venimos de lejos, esta batalla nuestra es larga, esta batalla nuestra tiene más de 500 años en esta Tierra. Aquí estamos los hijos de Guaicaipuro ¿quién se siente aquí Guaicaipuro? Todos somos Guaicaipuro y su grito de guerra contra el imperio español Ana karina rote... de ahí venimos nosotros, de la resistencia aborigen, de la resistencia india, de la resistencia negra, de los explotados, de los dominados de siempre. Ha sido larga la batalla, nosotros somos ¡los hijos de Simón Bolivar! ¡Las hijas de Simón Bolívar! Nosotros somos los patriotas del 05 de julio, del 19 de abril, nosotros somos los soldados de José Félix Ribas en la Victoria (Discurso de cierre de campaña en la Avenida Simón Bolivar, pág. 3).

Estos ejemplos nos muestran lo importante que es el pasado, no solo para la campaña de Hugo Chávez, sino para su movimiento político en general, al grado de decirse orgulloso de ello, originario de ese pasado histórico que los diferencia del grupo político opositor, y por tanto, reitera dicha característica una y otra vez en sus discursos.

Como se pudo observar, este eje explica de alguna manera aquellos recursos extralingüísticos que acompañan al discurso y que lo convierten en emotivo, y son una forma más en la que los equipos de campaña hacen que el evento en general sea eufórico y que cuente con rasgos emotivos que impacten en el auditorio; todo ello con un único objetivo, el de la persuasión.

\section{E) EJE DE CAUSALIDAD/AGENTIVIDAD}

Se trata de la "determinación de una causa o agente de influencia en las actitudes emocionales ante un acontecimiento" (2011: 200). Dicho de otra forma, se trata de mostrar el origen de las variaciones de la emoción que despierta la atribución de responsabilidades de determinados acontecimientos. Plantin nos advierte que en el caso de cuestiones políticas este tipo de atribuciones crea en el espacio público indignación política, pues atribuye responsabilidades sobre ciertos agentes. Se trata de un recurso ampliamente utilizado por el discurso populista, aunque su uso no es exclusivo de este género discursivo.

El uso de este eje no es generalizado, dado que algunos de los políticos analizados lo utilizan en cada uno de sus discursos, aunque otros parecen preferir evitar el tema. Así pues, por un lado, observamos que para Hugo Chávez éste es un eje que le ayuda mucho en su argumentación, sobre todo cuando menciona todos los errores que encontró al llegar al poder. Y por tal motivo, todos aquellos problemas económicos, politicos y sociales que aquejaban a la sociedad venezolana antes de que el grupo chavista llegara al poder, son atribuidos a otros grupos políticos, como se observa a continuación:

[20] porque Venezuela hasta hace una década era doblemente dominada, doblemente maniatada, primero por el imperio yanqui y todo su aparataje de dominación, que no 
tiene que ver necesariamente con los Marines y con las bombas, aún cuando ahora han puesto de nuevo las invasiones, los bombardeos, y las agresiones armadas contra los pueblos; era lo que había aquí, la dominación imperial, era política, un Estado subordinado al poder transnacional del imperio, una economía subordinada al poder imperial de las transnacionales económicas, incluso buena parte de nuestra identidad nacional había sido pulverizada. Pero además de ese ámbito de dominación imperial Venezuela, ya lo dije, estaba sometida a un segundo nivel complementario de aquel, por supuesto, se trata de la dominación burguesa criolla, doble mecanismo de dominación: el imperio y la burguesía. Pues nosotros hemos logrado en una década romper las cadenas de la dominación imperial, y romper buena parte de las cadenas de la dominación burguesa sobre el pueblo venezolano, aún cuando el proceso de independencia no termina todavía, y por eso digo aquí en la propuesta, defender, expandir, profundizar y consolidar... (Inscripción de la Candidatura de la Patria de Hugo Chávez, Pág. 9)

Este fragmento muestra la manera en que Chávez responsabiliza de todos los problemas que encontró al llegar al poder. En primer lugar al gobierno norteamericano, y en segundo lugar, al grupo burgués venezolano, buscando con ello quitarse en cierta medida responsabilidades.

En cambio, para Peña Nieto o incluso para Cristina Fernández es más dificil el tema, debido a que la dificil situación por la que atraviesan ambos países son consecuencia de malas administraciones de personas que pertenecieron a sus mismos partidos políticos, el PRI y el PJ respectivamente. Por tanto, usar este tema puede resultar contraproducente para ellos, por tal motivo su empleo parece limitado en ambos casos, como se observa a continuación:

[21] ¿Qué hubiera pasado en la Argentina? Hagamos un ejercicio por favor, ¿qué hubiera pasado en la Argentina de hace 7, 8, 9, 10 años atrás, con una crisis global de las características que hoy tenemos? Si cuando estuvo el tequila o cuando tuvo el problema Brasil, se nos vino el mundo encima, imagínense ese país en este momento. Entonces, ¿no es hora de reconocer algunas cosas? (Discurso emitido en el Teatro Coliseo para el $F p V, \S 19)$.

Lo que Cristina Fernández hace aquí no es responsabilizar a nadie, a lo sumo hace referencia a lo mal que se encontraba el país sudamericano, pero quizás prefiere no mencionar a los agentes culpables, pues algunos de ellos son del mismo partido al que pertenece. Algo similar ocurre con el candidato mexicano, tras siete décadas de gobierno del PRI, partido que lo abandera, Enrique Peña prefiere evitar el asunto.

\section{F) NORMAS}

El efecto que provoca una emoción "varía según la posición del acontecimiento dentro del sistema de valores de la persona en la que se construye la emoción" (Plantin, 2011: 200). El político al verse frente a la necesidad de persuadir al ciudadano de adherirse a su propuesta politica, necesita utilizar valores e intereses culturales que despierten emociones en su interlocutor. Por tal motivo, no podemos hablar de la naturaleza de la emoción del sujeto de manera abstracta, pues los sentimientos varian de acuerdo a cada sociedad y época (Plantin, 2011: 181), tal y como nos lo muestra el propio 
autor con el siguiente ejemplo. En un estado de guerra, sin importar de cuál se trate, un hombre observa a un muerto, ¿de qué manera reaccionará el hombre que observa? Plantin responde que sus reacciones pueden ser múltiples, debido a que dependerán de quién sea el muerto. Si se trata de un enemigo, el hombre que observa tendrá una reacción de alegría, o al menos de alivio, pues su vida está a salvo, al menos de esa persona. En cambio, si se trata de una persona desconocida, las reacciones del observador podrán ser de pavor (al pensar que el siguiente puede ser él), de piedad, e incluso de indiferencia (no hay que olvidar que las guerras son situaciones en donde la muerte se convierte en algo normal, por tal razón, una muerte más no impactará de manera significativa al hombre que observa). Pero algo muy distinto implicará si el muerto se trata de un familiar, un ser querido, o incluso un conocido, ya que provocará tristeza e incluso depresión. Como puede observarse en este ejemplo, un mismo acontecimiento (en este caso la muerte) es capaz de provocar distintas reacciones, y con ello diversas emociones, pero éstas se encuentran determinadas por el sistema de valores de cada individuo y por el contexto, tal y como se puede observar en el ejemplo anterior.

En este eje las normas de la gente están influenciadas en gran medida por el tipo de evento del que se trate. Dicho de otra manera, la normatividad del propio evento determinará la manera de proceder de los asistentes. Así por ejemplo, la gente se comporta de diferente manera si se trata de un evento masivo que de un evento más exclusivo de allegados cercanos al candidato. Obsérvese los siguientes ejemplos:

[22] ¡Ajá! Compañero, por favor el de la franela amarilla que levantó la mano rápido o compañera, a ver, como tienes gorra jah! Compañera, perdón, ¿de dónde eres tú, por favor? Y ¿a qué comando perteneces, compañera?

Militante del PSUV: Calabozo, estado Guárico.

Presidente Chávez: Otra calaboceña.

Guárico con la cola ¡coleadores atrás!

Militante del PSUV: Guárico, Guárico.

Presidente Chávez: ¿Y cómo te llamas?

Militante del PSUV: Jenny Moyetones.

Presidente Chávez: ¿̇h?

Militante del PSUV, Jenny Moyetones: Jenny Moyetones.

Presidente Chávez: Yenny, ajá, cuéntanos ¿cómo es eso allá en Calabozo? ¿Cómo es eso del comando?, ¿tú eres del comandito, allá?

Militante del PSUV, Jenny Moyetones: Pertenezco a la UBC, soy... pertenezco al Comando de la Unidad educativa José Maria Vargas.

Presidente Chávez: ¿Ese es el centro de votación?

Militante del PSUV, Jenny Moyetones: El centro de votación.

Presidente Chávez: ¿Eso queda en Calabozo?

Militante del PSUV, Jenny Moyetones: En Calabozo.

Presidente Chávez: Ajá, correcto.

Militante del PSUV, Jenny Moyetones: Municipio Miranda.

Presidente Chávez: ¿Y, y entonces?

Militante del PSUV, Jenny Moyetones: Bueno, ahí Comandante yo cuento con dos mesas, 569 votantes y tenemos 36 listas... alistados del uno por diez, aparte de eso contamos con 349 patrullas (Reunión con la maquinaria electoral del PSUV, Pág. 3). 
[23] No, sin silbidos para nadie, acá no se estigmatiza a nadie, cada uno sabe lo que hizo y lo que no hizo. No, no, de ningún modo, con mucho respeto para todo el mundo (Confirmación de la candidatura a la reelección de Cristina Fernández de Kirchner, §35)

En el Fragmento 22 se observa la manera en que interactúa Hugo Chávez con una militante del Gran Polo Patriótico. Dicha interacción se da en una situación de desigualdad: uno con un mando superior, en cambio la otra persona en un mando inferior y mostrando respeto al de mando superior, Esto se nota principalmente en la manera en que uno puede preguntar y el otro solamente responder lo que se le pregunta. En cambio, en el Fragmento 23 no existe interacción, al menos no como en el caso anterior. Más bien, al tratarse de evento masivo la gente tiene la libertad de gritar, aplaudir, abuchear, lo que sea necesario a fin de mostrar el apoyo de los presentes hacia lo que el emisor va diciendo en su discurso. No obstante, en este caso a la candidata no le gusta la reacción de su auditorio, por ello les pide que lo dejen de hacer. Se tratan pues de normas distintas entre ambos ejemplos, en donde además de emociones, también las normas varian no solo entre candidatos, sino entre los discursos dependiendo de quién sea el receptor y la personalidad del emisor.

\section{Conclusión}

Debido a la trascendencia que tiene el discurso político emitido durante las campañas electorales es necesario profundizar en su estudio. Para tal objetivo, se ha propuesto el estudio comparativo de tres distintos discursos emitidos durante las campañas electorales pertenecientes a los políticos ganadores de las elecciones presidenciales de Argentina, México y Venezuela respectivamente. A través de dicha comparación y partiendo de la propuesta teórica de Christian Plantin, se ha podido mostrar cómo elementos provenientes del contexto que rodea los actos en los cuales son emitidos dichos discursos, logran reconfigurarlos, dotándolos de mayor emotividad.

Una vez analizado el corpus discursivo, se puede observar que los ejes propuestos por Plantin nos ayudan a comprender mejor la construcción de un discurso emotivo, como es el caso del discurso político de campaña. Y aunque algunos ejes son utilizados en los tres casos analizados, en otros no lo son, al menos eso nos indica la muestra seleccionada. Así, cuestiones como el tipo de evento, las personas incluidas, el eje de intensidad/cantidad y las normas son utilizados de igual manera en los tres casos de interés. En cambio, ejes como el de espacio/tiempo y el de causalidad/agentividad son utilizados de distinta manera o incluso son evitados. La razón de lo anterior se debe a los intereses que tiene el orador en cada uno de los discursos, así mientras que para el candidato venezolano la necesidad de remarcar la causalidad/agentividad por parte del gobierno norteamericano y la burguesía local, en el caso argentino y mexicano los oradores buscan omitirlo, pues en ambos casos la causalidad/agentividad estaria en manos de gente que pertenece al mismo partido que los candidatos. En cambio, aspectos como las 
personas incluidas en el discurso presentan los mismos rasgos en los tres casos, ya que incluyen tanto al orador (es decir, el politico en campaña) como al auditorio.

Así pues, una vez descritos estos seis ejes se cuenta ya con una visión global de la situación emocional que rodea el discurso politico de campaña de los tres estudios de caso propuestos. Con ello y mediante la observación del fenómeno extralingüístico ha sido posible delimitar los acontecimientos discursivos a partir de todos los ejes analiticos ofrecidos por la propuesta de Christian Plantin.

\section{REFERENCIAS}

CHARAUDEAU, P. (2009) "La argumentación persuasiva. El ejemplo del discurso político", en Shiro M. \& alii, Haciendo discurso. Homenaje a Adriana Bolivar, Facultad de Humanidades y Educación, Universidad Central de Venezuela, Caracas: 277-295.

COCKCROFT, J. D. (2001): América Latina y Estados Unidos: historia y politica país por país. México: Siglo XXI.

FAIRCLOUGH, N. (2003): "El análisis crítico del discurso como método para la investigación en ciencias sociales" en Métodos de Análisis Crítico del Discurso. Barcelona: Gedisa.

FAIRCLOUGH, N. e I. (2012): Political discourse Analysis: A method for advanced students. New York: Routledge Editorial.

FOUCAULT, M. (2002): El orden del discurso, Barcelona: Tusquets.

GILBERT, M. A. (2004): "Emotion, Argumentation and Informal Logic" Informal Logic (vol. 24, núm. 3): 245-264.

GILBERT, M. A. (1997): "Prolegomenon to a Pragmatics of Emotion" en Proceedings of the Ontario Society for the Study of Argumentation. Canadá: St. Catherine's Brock University.
GILBERT, M. A. (1995): "Coalescent Argumentation" Argumentation (Vol.9 $\quad$ No.5): 837. https://doi.org/10.1007/BF00 744761

GONZALEZ CASANOVA, P. (1975): La democracia en México. 7a. Edición, México: Ed. Era.

HAIDAR, J. (2002): El movimiento estudiantil del CEU: análisis de las estrategias discursivas y de los mecanismos de implicitación. México: UNAM.

HUNTINGTON, S. P. (1991): The Third Wave: Democratization in the Late Twentieth Century. Oklahoma: University of Oklahoma Press.

O'DONNELL, G. et al. (1986): Transitions fron Authoritarian Rule, Prospectos for Democracy. 4 vol., Baltimore: Johns Hopkins University Press.

O'DONNELL, P. \& SCHMITTER (2003): "Democracia, desarrollo humano y ciudadanía: reflexiones sobre la calidad de la democracia en América Latina" en Democracia, desarrollo humano y derechos humanos, Homo Sapiens, Rosario: 25-147

PLANTIN, Ch. (2011): Les bonnes raisons des émotions: principes et méthode pour l'étude du discours émotionné. Bern : Peter Lang. 
PRZEWORSKI, A. (1991): Democracy and the market, Cambridge, Cambridge University Press.

VERON, E. (1987): "La palabra adversativa". El Discurso Politico. Buenos Aires: Hachette.

VERON, E. (1986): Perón o muerte. Los fundamentos discursivos del fenómeno peronista.
Buenos Aires: Editorial Legasa.

WODAK, R. (2003): "De qué trata el análisis crítico del discurso (ACD). Resumen de su historia, sus conceptos fundamentales y sus desarrollos" en Métodos de Análisis Crítico del Discurso. Barcelona: Gedisa: 17-34. 